\title{
DEILAGAON, A NEW GENUS OF INDO-MALAYAN AND PAPUAN FIG WASPS (HYMENOPTERA, CHALCIDOIDEA, AGAONIDAE)
}

\author{
by \\ J. T. WIEBES \\ Department of Systematic Zoology, University of Leiden, The Netherlands
}

\begin{abstract}
Introduction of the new genus Deilagaon with descriptions of new species chrysolepidis (type-species) from the Philippines (type-locality Luzon, ex Ficus chrysolepis Miq.), Celebes, New Guinea (ex $F$. novoguineensis Corner), Bismarck Archipelago, Solomon Isls.; and annulatae from Thailand, Malaya (ex $F$. depressa Bl.), Sumatra, Borneo (type-locality N. Borneo, ex $F$. annulata B1.), Philippines. Included is also Ceratosolen megarhopalus Grandi (1923) from Thailand, Malaya, Sumatra, Java, Borneo, Philippines (Balabac Isl.).
\end{abstract}

\section{INTRODUCTION}

Among large collections of fig wasps caught at light, received for study from the Bernice $P$. Bishop Museum at Honolulu, many female specimens have strikingly large, clubbed antennae. Some could also be reared from figs, which made possible a correlation with specimens of the male sex. In characters of both male and female, the species resemble Waterstoniella Grandi (1921), a relationship confirmed by the host records of the figs identified by Prof. E. J. H. Corner, of Cambridge. Yet, the species appear to form a separate group, here described as a new agaonid genus in the subfamily Blastophaginae.

More material was made available by the Hawaiian Sugar Planters' Association, Honolulu (HSPA), the Rijksmuseum van Natuurlijke Historie, Leiden (RMNH), the United States National Museum, Washington, and the Zoological Museum of Copenhagen (material collected by the Noona Dan Expedition to the Philippines, Bismarck Archipelago, and the Solomon Islands).

This paper is dedicated to Professor G. Barendrecht on the occasion of his retirement, in great respect and friendship.
Deilagaon n. gen.

Diagnosis. - Female antenna clubbed, notably the seventh to eleventh segments transverse, with many sensilla (fig. 3). Apical tooth of the mandible not sharp and prolonged as in Waterstoniella Grandi.

Type-species. - Deilagaon chrysolepidis $\mathbf{n}$. sp.

Additional species.- Deilagaon annulatae n. sp., Ceratosolen megarhopalus Grandi, 1923.

Hosts. - The species seem to be associated with figs of the section Conosycea (Miq.) Corner viz., Ficus annulata Bl., chrysolepis Miq., depressa Bl., and novoguineensis Corner. Judging from the distribution of Deilagaon megarhopalum. Ficus globosa Bl. may be a possible host (see Corner, 1965: 12, for its distribution). It should be noted that $F$. arnottiana Miq. was recorded as the host of Blastophaga arnottiana Joseph, 1953, a species not closely related to the three recorded in the present paper.

\section{KEY TO THE SPECIES (FEMALES)}

1. Ovipositor short, $1-1 \frac{1}{2}$ times the length of the gaster, shorter than the body. Longitudinal diameter of the compound eye up to four times as long as the cheek. Fifth and sixth segments of the antenna not fully integrated in the club .................. 2

- Ovipositor $3-4$ times as long as the gaster, $1 \frac{1}{2}-2$ times as long as the body. Longitudinal diameter of the eye eight times as long as the cheek. Fourth antennal segment short; fifth and sixth segments shaped so as to form part of the club .............. chrysolepidis

2. Longitudinal diameter of the eye $3-4$ times as long as the cheek. Fourth antennal segment slender; fifth and sixth segments shaped so as to form the prolonged stalk of the club. Mandibular appendage narrow, with ca. 15 lamellae. 
Postmarginal vein of the fore wing only half as long as the stigmal ............... annulatae Longitudinal diameter of the eye twice as long as the cheek. Fourth segment short; fifth and sixth segments shorter than in annulatae, the sixth a simple ring without sensilla. Mandibular appendage wide, with up to nine transverse lamellae. Postmarginal vein almost three times the length of the stigmal ...... megarhopalum

Deilagaon chrysolepidis n. sp.

(Figs. 1-25)

Type-material. - Series $\% ९, \delta^{\circ}$, Philippines, Luzon, Laguna, Mt. Banahao, 900 m, 8.XI. 1964, leg. J. T. Wiebes, ex Ficus chrysolepis Miq. (J. V. Pancho no. 4170 , det. E. J. H. Corner) (RMNH 759, holotype $q$ and paratypes $q \delta$ slidemounted).

Female. - Head (fig. 4) shorter than wide across the compound eyes $(11: 13)$; the longitudinal diameter of the eye about eight times as long as the cheek. Two large lateral ocelli, the median one atrophied. Antenna (figs. 3, 9) elevensegmented; the scape relatively slender, three times as long as wide; the pedicel one-quarter of the length of the scape; the appendage of the third segment very sharply pointed, reaching beyond the apex of the fifth segment; the fourth segment short, as long as the pedicel; the fifth to eleventh segments shaped so as to form a large club, each with one or two apical rows of many sensilla (especially on segments 6-10): there are distinct differences with the antenna of $D$. megarhopalum, the sixth segment of which is small, as if interrupting the club and bears few or no sensilla. Trophi (figs. 1-2): the mandible has two teeth, one gland, and about ten vague ventral lamellae; the appendage with seven lamellae, drawn out medially; the labium with two apical setae, the maxillae with a large number of lateral setae.

Thorax without pollen pockets, the mesosternum with many small setae. The dorsal sclerites much as in Grandi's figure of $D$. megarhopalum (Grandi, 1924: fig. vii, 1), but the pronotum without the concentration of setae along the midline. Wings (fig. 12): fore wing (5:2), $1.7 \mathrm{~mm}$ long; the submarginal and marginal (the two combined), stigmal, and postmarginal veins approximately in ratio $17: 2: 3$; distinct venae spuriae radiate from the stigma. Hind wing ( $4: 1), 0.9 \mathrm{~mm}$ long. Fore leg (fig. 8): the dorsal armature of the tibia consisting of three teeth, two of which are antiaxial in position, while the axial one is small and not very prominent; the tarsal segments approximately in ratio $10: 4: 3: 3: 7$. Mid leg: the tarsal segments approximately in ratio $7: 3: 3: 2: 4$. Hind leg (figs. 10-11): the spines on the axial surface of the tibia are sharp, not peg-like, and the ventral spurs are relatively short; the axial spur has two teeth of equal length (the dorsal part spatulate, the ventral sharp), while the antiaxial spur also has two, normal teeth; the tarsal segments approximately in ratio $9: 4: 4: 3: 4$, with ventral spines and a heavy plantar fringe.

Gaster. The hypopygium (fig. 5) rather blunt, with small warts in between the arms of the $V$. Spiracular peritreme of eighth urotergite, fig. 6; pygostyle, fig. 7. Ovipositor four times as long as the gaster.

Length (head, thorax, and gaster), ca. $3 \mathrm{~mm}$. Colour yellowish.

Male (fig. 21). - Head (fig. 19) subcircular in outline; small eyes are situated laterally, in the frontal quarter of the head capsule. Antennae situated in a common groove; the scape (fig. 13) of approximately the same length as the club, the pedicel not quite half as long, the single anulus very short. Mandible (fig. 24) bidentate, with one gland; other mouthparts atrophied.

Thorax (fig. 19): the pronotum very long, with hyaline borders laterad of the longitudinal grooves for the reception of the dorsal edge of the fore femora (see fig. 21); the posterior sclerite two-thirds of the length of the pronotum; the propodeum differentiated from the anterior part of the posterior sclerite by a dark, sinuate line; the spiracular peritremata rather large. Fore leg with a very large femur, and a short, plate-like coxa; the tibia (fig. 14) armed with five antiaxial teeth i.e., two dorsad and three ventrad of the insertion of the two-segmented tarsus $(4: 3)$, with stout setae and spines. Mid leg (fig. 20) slender, not visible in lateral view of the male, its trochanter, femur, tibia, and tarsus approximately in ratio $6: 5: 4: 3$, the tarsus with two slender claws. Hind leg (fig. 23): the tibia with an antiaxial crest of two apical teeth, a tooth in the dorsal angle, and a bicuspidate ventral tooth (fig. 22 ); the three tarsal segments approximately in ratio $8: 4: 7$, with ventral spines.

Gaster. The first two gastral sternites more heavily sclerotized than usual. Genitalia simple. 


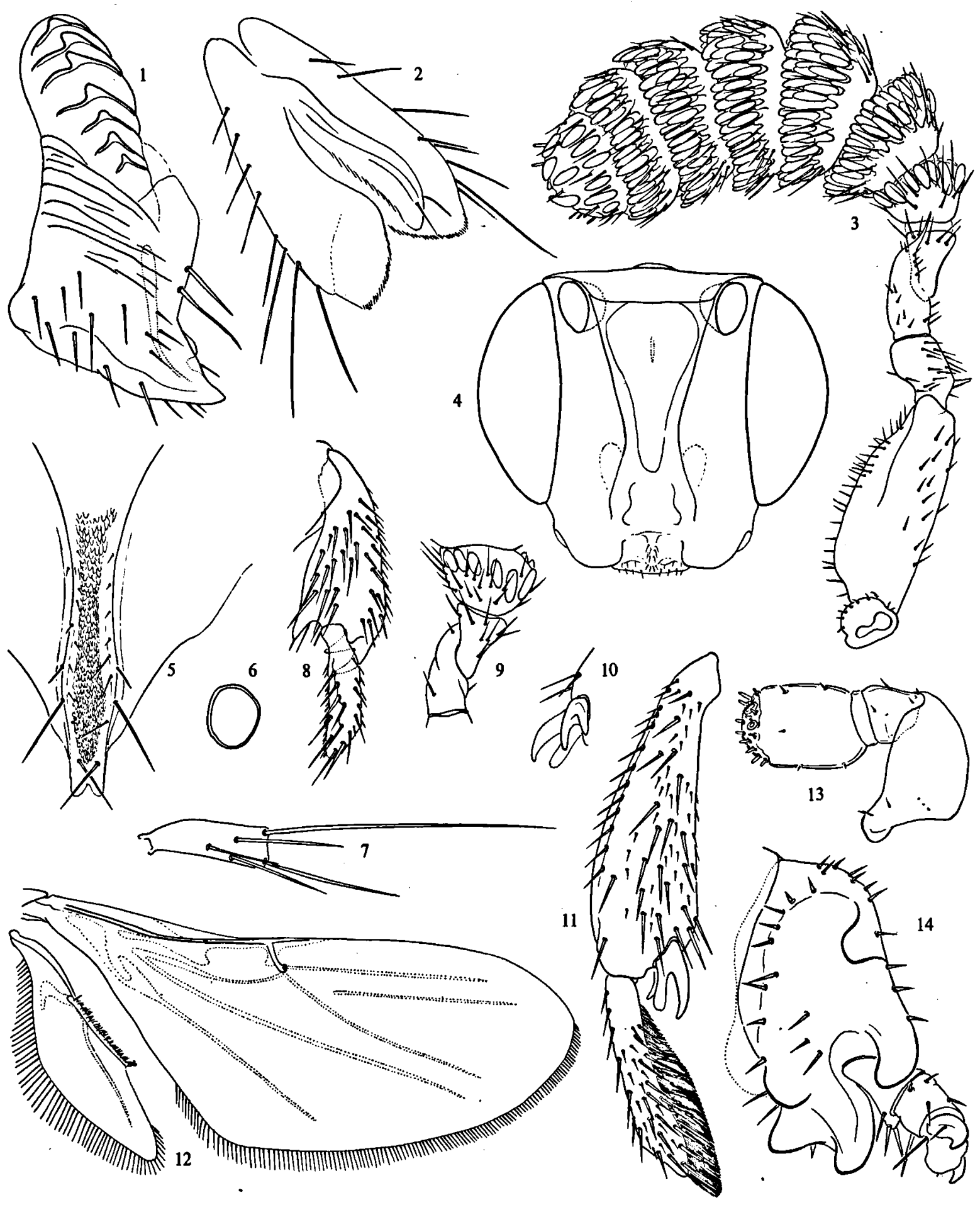

Figs. 1-14. Deilagaon chrysolepidis n. sp. (1-12, female holotype; 13-14, male): 1, mandible; 2, maxillo-labial complex, oblique ventral; 3, antenna, antiaxial; 4, head; 5 , hypopygium; 6 , spiracular peritreme of eighth urotergite, outline; 7 , pygostyle; 8, fore tibia and metatarsus, axial; 9, detail of antenna, axial; 10, apex of hind tibia, antiaxial; 11 , hind tibia and metatarsus, axial; 12, wings (pubescence of membrane omitted); 13, left antenna, dorsal; 14, fore tibia and tarsus, antiaxial. Figs. 1, 2, 6, 7, $\times 335 ; 3,8-11, \times 200 ; 4-5, \times 135 ; 12, \times 55 ; 13-14, \times 280$. 
Length (head and thorax), ca. $1.0 \mathrm{~mm}$. Colour light brown.

Distribution. - The map (fig. 25) contains a survey of the localities where light catches were made; apart from the type sample, the following samples were reared from figs:

Series $q \%, \delta^{\star} \sigma^{*}$ Philippines, Luzon, Laguna, Mt. Makiling, leg. F. X. Williams, ex Ficus longipedunculata: 31.V.1921 ( 6 १ , $\left.25 \sigma^{\circ} \sigma^{\circ}\right), 1-2$. VI.1921 (1 \%), 23-24.VI.1921 (series $\$$, $\delta^{\circ} \delta^{\circ}$; 10 of each in RMNH 2489), 24.VI.1921 (series $q \%$, $\left.\delta^{\circ} \delta^{\circ}\right), 12.11 .1922$ (12 $\%$, $13 \delta^{\circ} \sigma^{\circ}$ ) (all HSPA).

Series $\& \%, \delta^{\pi} \delta^{*}$, Philippines, Luzon, Quezon, National Park Atimonan, $350 \mathrm{~m}, 23 . X I I .1964$, leg. J. T. Wiebes, ex Ficus chrysolepis Miq. ( J. V. Pancho nos. 4228, 4233, det. E. J. H. Corner) (RMNH 760, 761).

One $q$, series $\sigma^{\circ} \sigma^{\circ}$, New Guinea (Northeast), Morobe dist., Morobe, leg. E. J. H. Corner, ex Ficus novoguineensis Corner (New Guinea Field no. 15626, det. Corner)(RMNH 2463).

Remarks. - There is a great variation in the size and shape of the axial spur of the female hind tibia, in some instances even between specimens reared from one and the same fig. Some of the variations found in the Philippines are illustrated in figs. 15-17; the shorter spurs seem to occur in specimens with the longer ovipositors. The specimens from New Guinea and adjacent isles are characterized by quite heavy spurs (fig. 18), while the ovipositor is as short as in the short-spurred Philippine specimens. The few females studied from the Solomons have short spurs, and the ovipositor is rather short $(11 / 2$ times the length of the body); these specimens are rather large.

I postpone a taxonomical distinction on this variation until new samples, preferably reared from figs, and properly prepared ${ }^{1}$, will be available for study. One sample was reared from $F$. novoguineensis Corner (1961: 84-85; "forsan $F$. chrysolepidis varietas ..."); it contains mainly males indistinguishable from those from the Philippines. Ficus longepedunculata (Merr.) Elm. is the same as $F$. chrysolepis Miq. (Corner, 1965: 12).

\section{Deilagaon annulatae $n$. sp.}

(Figs. 25-38)

Type-material. - Series $\% \%, \delta^{\circ} \delta^{\circ}$, North Borneo, Poreng village, 1800 ft., 9.VI.1961, leg. E. J. H. Corner, ex Ficus annulata Bl. (det. Corner) (RMNH 655, holotype $q$ and paratypes $\% \delta$ slide-mounted).

1) The specimens collected at light are dried, and full of lepidopterous scales.
Female. - Head (fig. 26) slightly shorter than wide across the compound eyes $(14: 15)$; the longitudinal diameter of the eye three to four times as long as the cheek. Two large ocelli, the median one atrophied. Antenna (fig. 36) elevensegmented; the scape rather robust, twice as long as wide and $31 / 2$ times as long as the pedicel, with a row of long setae along the anterior margin; the appendage of the third segment robust, blunt, not nearly reaching the apex of the fourth segment; the fourth segment slender, its length $2 \frac{1}{2}$ times its apical width, about twice as long as the pedicel; the fifth and sixth segments shaped so as to form the prolonged stalk of the clubbed antenna, the club being formed by the seventh to eleventh segments; the club segments have many sensilla on the antiaxial surface, but only three to six on the axial one, while the fifth and sixth segments bear two sensilla on either surface. Trophi (figs. 27-28): the apical tooth of the mandible acute, the subapical rounded; one gland; about ten ventral lamellae; the appendage with ca. 15 ventral lamellae, most of which are produced ventrally; the labium with one apical seta, the maxillae with a lateral row, and three long subapicals.

Thorax without pollen pockets; the fore wing (3:1), $1.8 \mathrm{~mm}$ long, its submarginal and marginal (the two combined), stigmal, and postmarginal veins approximately in ratio $14: 2: 1$; the membrane with dense microtrichia; venae spuriae not always distinct. Hind wing (5:1), $1 \mathrm{~mm}$ long. Legs much like those of $D$. chrysolepidis (figs. 8, 10-11); the fore tarsi approximately in ratio $18: 8: 8: 7: 13$; mid tarsi, $10: 8: 7: 5: 11$. Hind leg: the axial tibial spur rather long and slender, the antiaxial more robust and bidentate; the tarsal segments approximately in ratio $20: 10: 9: 6: 10$, with a plantar fringe and axial spines.

Gaster. The hypopygium (fig. 30) more acute than that of $D$. chrysolepidis, without warts, not distinguishable from that of $D$. megarhopalum. Spiracular peritreme of eighth urotergite, fig. 31; pygostyle, fig. 32. Ovipositor $1 \frac{1}{2}$ times as long as the gaster.

Length (head, thorax, and gaster), ca. $2 \mathrm{~mm}$. Colour yellowish, the head somewhat darker.

Male. - Head (fig. 34) almost as wide as long (15:16); eyes atrophied. Antennae in a common groove; the scape (fig. 37 ) long and robust, with 


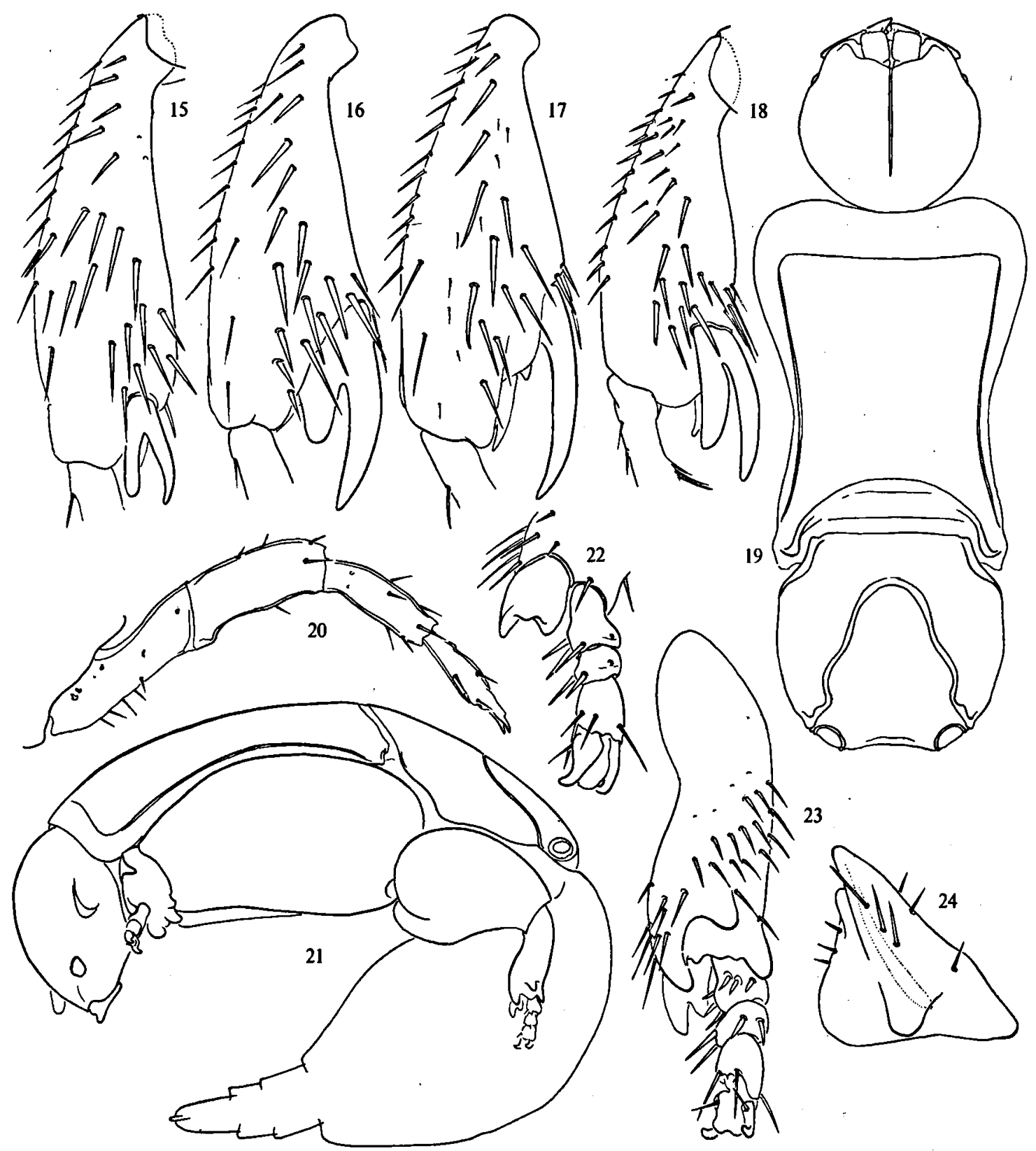

Figs. 15-24. Deilagaon chrysolepidis $\mathrm{n} . \mathrm{sp}$. (15-18, female; 19-24, male): 15-18, hind tibia in axial view, of specimens from: Luzon (15, Mt. Banahao; 16, Mt. Makiling), Palawan (17, Pinigisan), and New Guinea (18, Hollandia); 19, head and thorax; 20, mid leg, axial; 21, male in lateral view; 22, detail of hind leg, axial; 23, hind tibia and tarsus, antiaxial; 24, mandible, ventral. Figs. $15-18,20,22-24, \times 280 ; 19,21, \times 85$. 


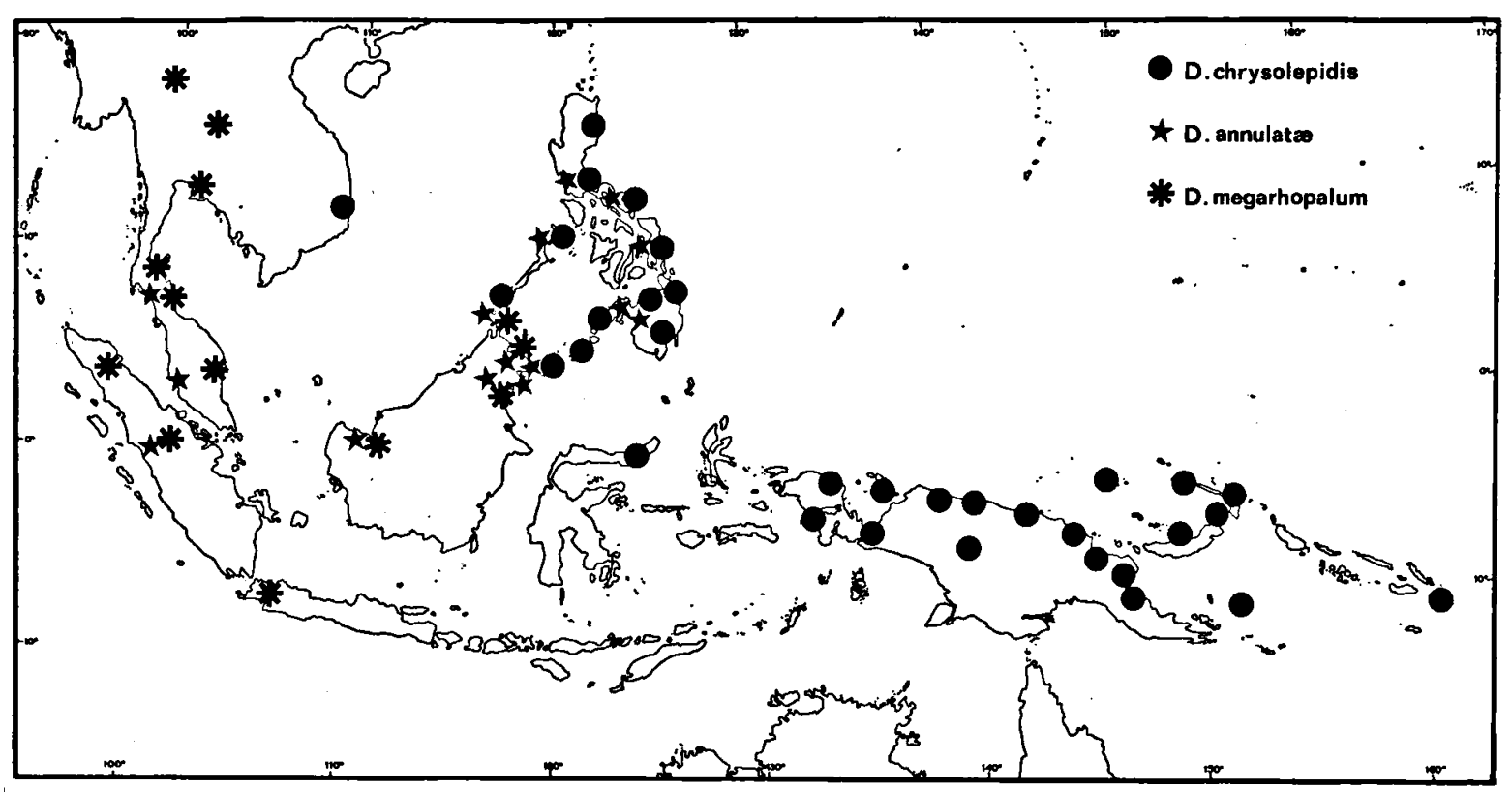

Fig. 25. Approximate localities of the specimens of Deilagaon.

antiaxial setae; the pedicel two to three times as long as the third and fourth segments combined, large, with distal sensilla. Mandible (fig. 33) bidentate, with two glands; the other mouthparts atrophied.

Thorax (fig. 35): the pronotum large, wider than long (5:4); the mesonotum and metanotum forming one sclerite (their boundary visible as lateral dark lines), and also incompletely fused with the propodeum; the spiracular peritremata small, subcircular. Fore leg (fig. 29) robust, the tibia with many setae; its apical armature consisting of four large teeth; the four tarsal segments approximately in ratio $3: 1: 1: 2$. Mid leg rather slender, the tarsal ratio approximately as $2: 1: 1: 1: 2$. Hind leg (fig. 38): the tibia with an antiaxial crest of two apical teeth, a slender tooth at the dorsal angle, and a bicuspidate ventral tooth; the five tarsal segments approximately in ratio $7: 2: 2: 2: 5$, with ventral cones.

Gaster. Genitalia simple.

Length (head and thorax), ca. $1 \mathrm{~mm}$. Colour uniform yellowish.

Distribution. - The localities are indicated on the map (fig. 25). Apart from the type lot, one other sample was reared from a fig, viz.:

One \$, Malaya, Selangor, Sungei Tingii, leg. E. J. H. Corner, ex Ficus depressa Bl. (Singapore Field no. 34141, det. Corner) (RMNH 374).
Remarks. - Although in the description reference is made to some figures of $D$. chrysolepidis for comparison, the species is closer to $D$. megarhopalum (see Grandi, 1924, figs. vi-vii). It is easily distinguished by the larger eyes, the long row of setae on the scape, the slender fourth segment of the antenna, the larger number of (ventrally produced) lamellae on the narrow mandibular appendage, and the short postmarginal vein: these are all characters of the female, the male of $D$. megarhopalum being unknown.

The male of $D$. annulatae is much more robust than that of $D$. chrysolepidis, it is blind, the antenna has more segments, the fore tibia is quite normal, and the mid and hind tarsi are pentamerous as against respectively much reduced, and trimerous, in D. chrysolepidis.

Some localities seem to be outside the distributional area of the host fig as given by Corner (Ficus annulata; Corner, 1965: 12), and one sample was collected from the sycones of another species of fig, viz., F. depressa (see Corner, 1970: 543,640 , for the identification of Singapore Field no. 34141). In another group of fig wasps, too, one species of wasp was recorded from the same samples of $F$. annulata and $F$. depressa (Eujacobsonia mirabilis Grandi, 1923; Wiebes, 1967: 108109). 


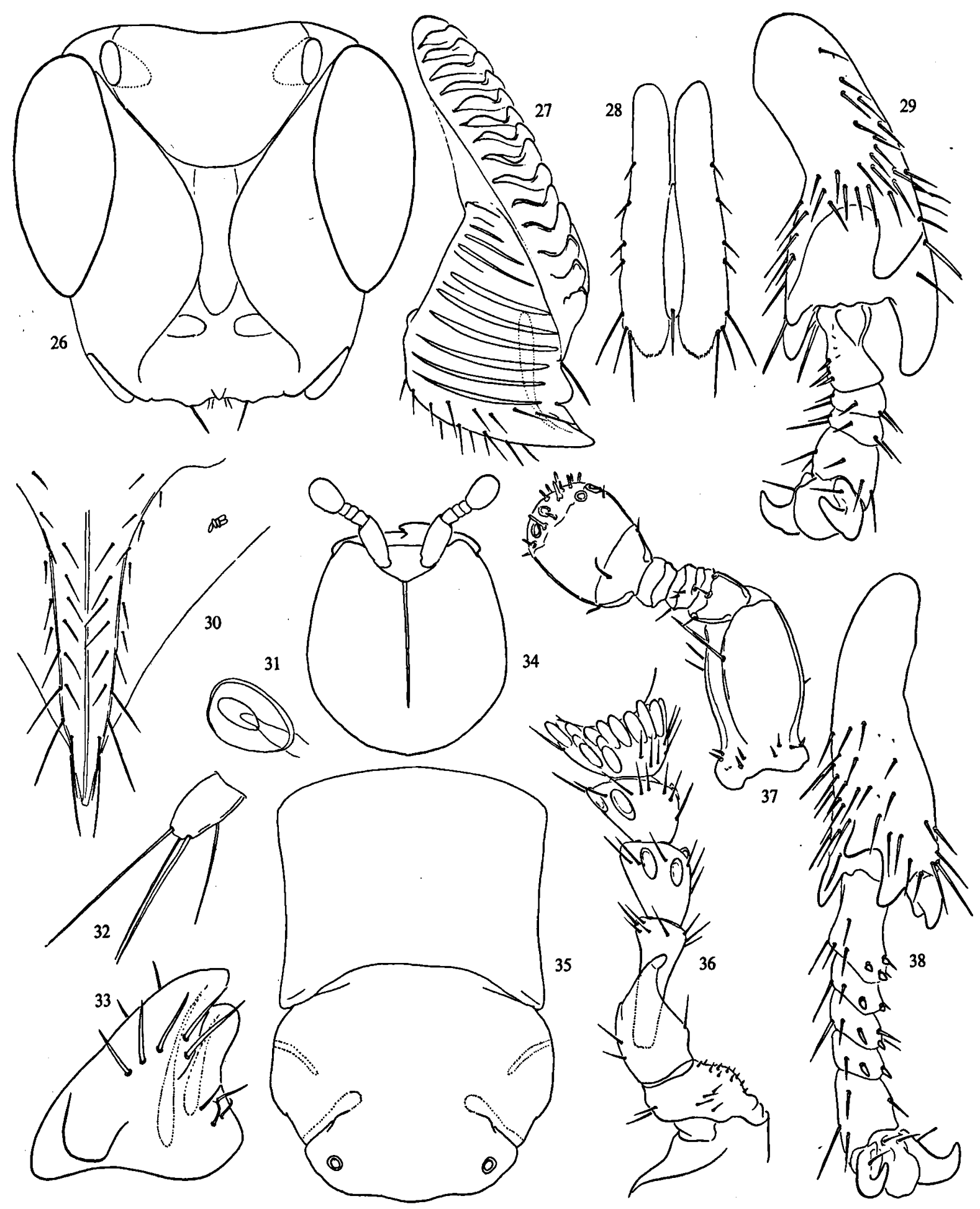

Figs. 26-38. Deilagaon annulatae $n$. sp. (26-28, 30-32, 36, female holotype; $29,33-35,37-38$, male): 26 , head; 27 , mandible; 28, maxillo-labial complex, ventral; 29, fore tibia and tarsus, antiaxial; 30, hypopygium; 31, spiracular peritreme of eighth urotergite, outline; 32, pygostyle; 33, mandible, ventral; 34, head; 35, thorax; 36, detail of antenna, antiaxial; 37, left antenna, dorsal; 38, hind tibia and tarsus, antiaxial. Figs. 26, 30, $\times 140 ; 27-29,31-33,36-38, \times 280 ; 34-35, \times 85$. 
Deilagaon megarhopalum (Grandi, 1923) n. comb. Distribution. - The localities are indicated on

Ceratosolen megarhopalus Grandi, 1923: 103-104 (description of $\$$, Sumatra, Fort de Kock, at light); 1924: 14-18, figs. vi-vii (description of $\%$, Sumatra); Wiebes, 1963: 84 (excluded from Ceratosolen). the map (fig. 25); all samples known to me are caught at light. Males of this species are not yet known.

\section{REFERENCES}

Corner, E. J. H., 1961. Taxonomic notes on Ficus Linn., Asia and Australasia. Addendum. Gdns' Bull., Singapore, 18: 83-97.

- 1965. Check-list of Ficus in Asia and Australasia with keys to identification. Gdns' Bull., Singapore, 21: 1-186.

$\rightarrow$ 1970. Ficus (Moraceae). Identification lists of Malaysian specimens (Rijksherbarium, Leiden), 37: 537-648b.

Grandi, G., 1923. Imenotteri dei fichi della fauna olartica e indo-malese (diagnosi preliminari). Annali Mus. civ. Stor. nat. Giacomo Doria, 51: 101-108.

-, 1924. Agaonini e Sycophagini olartici e indo-malesi. Boll.
Lab. Zool. gen. agr. R. Scuola Agric. Portici, 18: 1-31.

JoSEPH, K. J., 1953. Contributions to our knowledge of fig insects (Chalcidoidea: parasitic Hymenoptera) from India. IV. Descriptions of three new and records of four known species of Agaonini. Agra Univ. J. Res., 2: 267-284.

WIEBES, J. T., 1963. Taxonomy and host preferences of IndoAustralian fig wasps of the genus Ceratosolen (Agaonidae). Tijdschr. Ent., 106: 1-112.

,- 1967 . Indo-Malayan and Papuan fig wasps (Hymenoptera, Chalcidoidea). 6. The genus Eujacobsonia Grandi (Torymidae). Zooll. Meded. Leiden, 42: 107-115. 